\title{
Small-Signal Stability Analysis of Wind Power System Based on DFIG
}

\author{
Bin Sun, Zhengyou He, Yong Jia, Kai Liao \\ School of Electrical Engineering, Southwest Jiaotong University, Chengdu, China \\ Email: unixo@my.swjtu.edu.cn
}

Received April, 2013

\begin{abstract}
This paper focuses on the small-signal stability of power system integrated with DFIG-based wind farm. The model of DFIG for small-signal stability analysis has built; the 3-generator 9-bus WECC test system is modified to investigate the impacts of large scale integration of wind power on power system small-signal stability. Different oscillatory modes are obtained with their eigenvalue, frequency and damping ratio, the results from eigenvalue analysis are presented to demonstrate the small-signal stability of power system is enhanced with the increasing output of the wind farm.
\end{abstract}

Keywords: Small-Signal Stability; DFIG; Wind Power; Power System; Wind Farm

\section{Introduction}

As of the end of 2011, the installed capacity of wind power in China has reached $62.36 \mathrm{GW}$ [1], the planning and construction of large scale wind farm will be the inevitable trend of the development of wind power in China. Wind power has obvious characteristics of randomness, volatility and intermittent, this development affects the small-signal stability of the traditional power system, so it is significant to study the impacts of large scale integration of wind power on power system small-signal stability.

In [2], an aggregated wind farm model with DFIG based wind turbine for small-signal stability study is proposed to deal with the situation that the wind turbines operate receiving different incoming wind speeds. In [3], the 10-generator 39-bus New England test system is applied to assess the effect of the large scale wind farm on power system small-signal stability. In [4], the effect of wind power on the oscillations is investigated by gradually replacing the power generated by the synchronous generators in the system by power from either constant or variable speed wind turbines, while observing the movement of the eigenvalues through the complex plane.

The aim of this paper is to study the small-signal stability of wind power system based on DFIG. This paper is structured as follows, with DFIG model in section II, and section III describe the modified 3-generator 9-bus WECC system applied in the simulation and analysis. The small-signal stability analysis of DFIG based wind farm is described in section IV, with discussions and conclusions presented in section $\mathrm{V}$.

\section{Modeling of DFIG}

There are mainly three kinds of wind turbine widely used nowadays: the constant speed wind turbine with squirrel cage induction generator, the variable speed wind turbine with doubly fed induction generator (DFIG) and the direct drive synchronous generator. The main differences between the three schemes are the generating system and the way in which the aerodynamic efficiency of the rotor is limited during wind speed variations [5, 6]. As a matter of fact, each of the wind generating systems has its own advantages and disadvantages. Almost all newer larger wind generating system being produced are variable speed systems based on DFIGs, so DFIG based wind farm is the main object in this study.

As is well known, the rotor terminals of a DFIG are fed with a symmetrical three-phase voltage of variable frequency and amplitude fed through a voltage source converter usually equipped with IGBT based power electronic circuitry [7]. The basic topology of DFIG is shown in Figure 1.

\subsection{Turbine and Drive Train}

The mechanical power input to the wind turbine is considered as constant, so the pitch angle do not change during the period of study. In this paper, the two-mass drive train model [8] is considered and the dynamics can be expressed by the following differential equations [9]:

$$
\begin{gathered}
\frac{d \omega_{r}}{d t}=\frac{1}{2 H_{g}}\left(T_{s h}-T_{e}\right) \\
\frac{d \theta_{t}}{d t}=\omega_{b}\left(\omega_{t}-\omega_{r}\right)
\end{gathered}
$$




$$
\frac{d \omega_{t}}{d t}=\frac{1}{2 H_{t}}\left(T_{m}-T_{s h}\right)
$$

where $\omega_{\mathrm{r}}$ is the generator angular speed, $\omega_{\mathrm{t}}$ is the wind turbine angular speed, $\omega_{\mathrm{b}}$ is the electrical base speed, $\theta_{\mathrm{t}}$ is the shaft twist angle, $H_{\mathrm{g}}$ is the inertia constant of the generator, $H_{\mathrm{t}}$ is the inertia constant of turbine, $T_{\mathrm{sh}}$ is the shaft torque, $T_{\mathrm{e}}$ is the electrical torque, $T_{\mathrm{m}}$ is the mechanical torque.

\subsection{Generator}

The most common way of representing DFIG for the purpose of simulation and control is in terms of direct and quadrature axes ( $d q$ axes) quantities, which form a reference frame that rotate synchronously with the stator flux vector [10]. The various variables are defined as: $e_{d s}^{\prime}=-K_{m r r} \omega_{s} \psi_{q r}, \quad e_{q s}^{\prime}=K_{m r r} \omega_{s} \psi_{d r}, \quad L_{s}^{\prime}=L_{s s}-\left(L_{m}^{2} / L_{r r}\right)$, $T_{r}=L_{r r} / R_{r}, K_{m r r}=L_{m} / L_{r r}, \omega_{e}=\omega_{b} \omega_{s}, \quad R_{2}=K_{m r r}^{2} R_{r}$ and $R_{1}=R_{s}+R_{2}$. Here, $e_{d s}^{\prime}$ and $e_{q s}^{\prime}$ are $d$-axis and $q$-axis voltage behind transient reactance, respectively, $\psi_{d r}$ and $\psi_{q r}$ are $d$-axis and $q$-axis rotor fluxes, respectively, $L_{\mathrm{ss}}$ is the stator self-inductance, $L_{\mathrm{rr}}$ is the rotor self-inductance, $L_{\mathrm{m}}$ is the mutual inductance between rotor and stator, $R_{\mathrm{r}}$ is the rotor resistance, and $R_{\mathrm{s}}$ is the stator resistance.

For balanced and unsaturated conditions, the corresponding DFIG model can be expressed as [10]:

$$
\begin{gathered}
\frac{\omega_{s} L_{s}^{\prime}}{\omega_{e}} \frac{d i_{d s}}{d t}=-R_{1} i_{d s}-\omega_{s} L_{s}^{\prime} i_{q s}+\frac{\omega_{r}}{\omega_{s}} e_{d s}^{\prime} \\
+\frac{1}{T_{r} \omega_{s}} e_{q s}^{\prime}-v_{d s}+K_{m r r} v_{d r} \\
\frac{\omega_{s} L_{s}^{\prime}}{\omega_{e}} \frac{d i_{q s}}{d t}=-R_{1} i_{q s}+\omega_{s} L_{s}^{\prime} i_{d s}+\frac{\omega_{r}}{\omega_{s}} e_{q s}^{\prime} \\
-\frac{1}{T_{r} \omega_{s}} e_{d s}^{\prime}-v_{q s}+K_{m r r} v_{q r} \\
\frac{1}{\omega_{e}} \frac{d e_{d s}^{\prime}}{d t}=-R_{2} i_{q s}-\frac{1}{T_{r} \omega_{s}} e_{d s}^{\prime}-\left(1-\frac{\omega_{r}}{\omega_{s}}\right) e_{q s}^{\prime}+K_{m r r} v_{q r} \\
\frac{1}{\omega_{e}} \frac{1}{d e_{q s}^{\prime}}=R_{2} i_{d s}-\frac{1}{T_{r} \omega_{s}} e_{q s}^{\prime}+\left(1-\frac{\omega_{r}}{\omega_{s}}\right) e_{d s}^{\prime}-K_{m r r} v_{d r}
\end{gathered}
$$

where $i_{\mathrm{ds}}$ and $i_{\mathrm{qs}}$ are $d$-axis and $q$-axis stator currents, respectively.

\subsection{Converter}

The converter model in DFIG comprises of two pulsewidth modulation invertors connected back to back via a dc link. The rotor side converter (RSC) and the grid side converter (GSC) act as a controlled voltage sources. The RSC injects an ac voltage at slip frequency to the rotor, whereas the GSC injects an ac voltage at power frequency to the grid and maintains the dc link voltage constant. The power balance equation for the converter model can be written as follows:

$$
P_{r}=P_{g}+P_{d c}
$$

where $P_{\mathrm{r}}, P_{\mathrm{g}}$ and $P_{\mathrm{dc}}$ are the active power at RSC, GSC and dc link, respectively, which can be expressed as follows:

$$
\begin{gathered}
P_{r}=v_{d r} i_{d r}+v_{q r} i_{q r} \\
P_{g}=v_{d g} i_{d g}+v_{q g} i_{q g} \\
P_{d c}=v_{d c} i_{d c}=C v_{d c} \frac{d v_{d c}}{d t}
\end{gathered}
$$

where $v_{\mathrm{dr}}$ and $v_{\mathrm{qr}}$ are $d$-axis and $q$-axis rotor voltages, respectively, $i_{\mathrm{dr}}$ and $i_{\mathrm{qr}}$ are $d$-axis and $q$-axis rotor currents, respectively, $v_{\mathrm{dg}}$ and $v_{\mathrm{qg}}$ are $d$-axis and $q$-axis voltage of the GSC, respectively, $i_{\mathrm{dg}}$ and $i_{\mathrm{qg}}$ are $d$-aixs and $q$-axis of the GSC, respectively, $v_{\mathrm{dc}}$ and $i_{\mathrm{dc}}$ are the voltage and current of the dc link capacitor, respectively, and $C$ is the capacitance of the dc capacitor. The direction of the currents and power flow are demonstrated in Figure 1.

\subsection{Controllers for DFIG}

As mentioned above, there are two back to back converters named RSC and GSC in DFIG system, some measures should be taken to control the two converters so that the DFIG can works in the appropriate condition. There are many kinds of control strategy we can choose to control the RSC and GSC, in this paper, we adopt the model of controllers built in [11], in which a decoupling control for the active power and reactive power of DFIG was developed.

\section{Generic Test System}

In this study, the 3-generator 9-bus WECC test system has been modified to assess the impact of a wind power plant based on DFIG on small-signal stability. The single line diagram is shown in Figure 2. The system contains 3 synchronous generators and 3 constant impedance loads. The large scale wind farm selected for simulation and

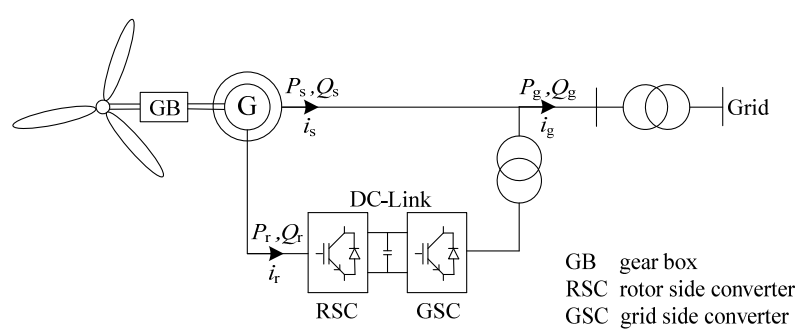

Figure 1. The basic topology of DFIG. 


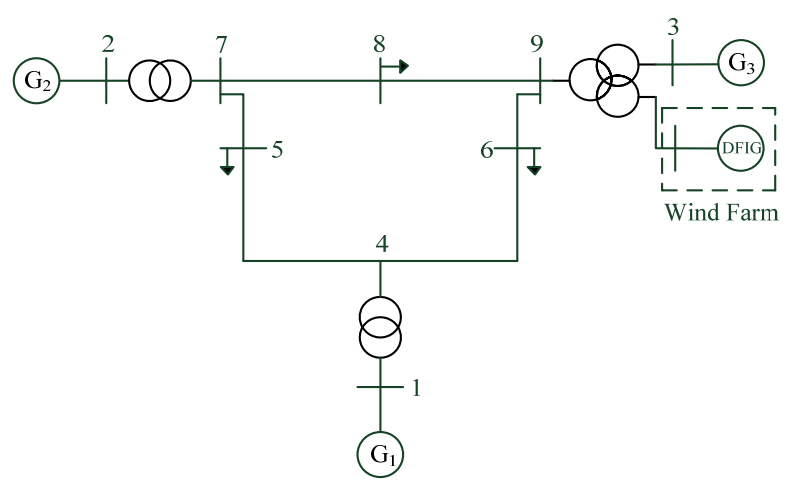

Figure 2. Single line diagram of the analyzed case network.

analysis consists of 50 DFIG-based wind turbines and the capacity of each turbine is $1.5 \mathrm{MW}$, so the total capacity of this wind farm is $75 \mathrm{MW}$. Here, a single equivalent model was used to represent all individual units within the wind power plant in order to avoid increasing computation time, so the modified WECC test system contains 3 synchronous generators and a wind turbine represented by a DFIG.

The base capacity and frequency of the system are 100 MVA and $50 \mathrm{~Hz}$. The active power and reactive power of 3 loads are adjusted, the active power and reactive power of bus 5 are 1.200 and 0.075 pu respectively, the active power and reactive power of bus 6 are 0.700 and 0.070 pu respectively, the active power and reactive power of bus 8 are 2.250 and 0.350 pu respectively. In order to ensure the power flow of the system unchanged, the output of synchronous generator $\mathrm{G}_{3}$ should be adjusted at the same time when increasing the output of wind farm. The single wind turbine parameters are as follows: $U_{\mathrm{N}}=0.69 \mathrm{kV}, S_{\mathrm{N}}=1.5 \mathrm{MW}, f=50 \mathrm{~Hz}, R_{\mathrm{s}}=0.01 \mathrm{pu}, X_{\mathrm{s}}=0.10$ pu, $R_{\mathrm{r}}=0.01 \mathrm{pu}, X_{\mathrm{r}}=0.08 \mathrm{pu}, X_{\mathrm{m}}=4 \mathrm{pu}, H_{\mathrm{m}}=3 \mathrm{kWs} / \mathrm{kVA}$, $K_{\mathrm{p}}=10, T_{\mathrm{p}}=3 \mathrm{~s}, K_{\mathrm{v}}=10, T_{\mathrm{E}}=0.01 \mathrm{~s}$.

\section{Small-Signal Stability Analysis}

Small-signal stability is the ability of the power system to maintain synchronism when subjected to small disturbances [12]. The disturbance is considered small enough to permit the equations that describe the resulting response of the system to be linearized and expressed in state-space form. Then, by calculating the eigenvalues of the linearized model, the small-signal stability characteristics of the system can be evaluated. In today's practical power systems, the small-signal stability problem is usually on of insufficient damping of system oscillations. Small-signal stability analysis using linear techniques provides valuable information about the inherent dynamic charateristic of the power system and assists in its design.

The most direct way to assess small-signal stability of the model of power system is via eigenvalue analysis.
When the wind farm output is $60 \%$ of its total capacity, i.e., the output of wind farm is $45 \mathrm{MW}$, at the same time, adjust the output of G3 to $40 \mathrm{MW}$ in order to keep the power flow constant. The eigenvalues associated with this case are given in Table $\mathbf{1}$. We can get 8 oscillatory modes, most of their oscillatory frequencies are between $0.1 \mathrm{~Hz}$ and $2.5 \mathrm{~Hz}$, so most of them are belong to lowfrequency modes. As a matter of fact, the low-frequency oscillation is of great harm to the safe and stable operation of the power system, so these low-frequency oscillation modes must be suppressed or eliminate by taking some efficient measures.

The eigenvalues will change with the increase of the output of wind farm. Since the damping ratios of mode I and mode II are relatively small, take them as an example, the eigenvalue, and frequency and damping ratio of mode I and mode II shifting with the output of wind farm varying are given in Table 2 and Table 3, the eigenvalue of mode I and mode II shifting with the output of wind farm increasing are shown in Figure 3 and Figure 4.

We can learn from two tables and two figures above, with the increase of the output of wind farm, the eigenvalues move to the left on the complex plane, the damping ratios become bigger and bigger, i.e., the small-signal stability of the power system is constantly enhanced. When the wind farm output at rated power, the system is the most stable. When the wind farm output below rated power, the larger the difference between output power and rated power, the more unstable the system is.

\section{Conclusion}

In this paper, we build the model of DFIG for smallsignal stability analysis and modify the 3-generator 9-bus WECC test system to study the impact of large scale integration of wind power on power system small-signal stability first. Then, different oscillatory modes are got by us with their eigenvalue, frequency and damping ratio.

Table 1. Main eigenvalues, frequencies and damping Ratios of the system.

\begin{tabular}{cccc}
\hline $\begin{array}{c}\text { Oscillatory } \\
\text { Mode No. }\end{array}$ & Eigenvalue & $\begin{array}{c}\text { Frequency } \\
(\mathrm{Hz})\end{array}$ & $\begin{array}{c}\text { Damping ratio } \\
(\%)\end{array}$ \\
\hline 1 & $-1.168 \pm \mathrm{j} 10.764$ & 1.713 & 10.788 \\
2 & $-0.268 \pm \mathrm{j} 7.628$ & 1.214 & 3.511 \\
3 & $-5.472 \pm \mathrm{j} 7.935$ & 1.263 & 56.770 \\
4 & $-5.171 \pm \mathrm{j} 7.794$ & 1.240 & 55.285 \\
5 & $-5.240 \pm \mathrm{j} 7.891$ & 1.256 & 55.319 \\
6 & $-3.647 \pm \mathrm{j} 0.633$ & 0.101 & 98.527 \\
7 & $-0.492 \pm \mathrm{j} 1.082$ & 0.174 & 41.393 \\
8 & $-0.463 \pm \mathrm{j} 0.717$ & 0.114 & 54.247 \\
\hline
\end{tabular}


Table 2. The eigenvalue, frequency and damping ratio of mode I shifting with the output of wind farm varying.

\begin{tabular}{cccc}
\hline $\begin{array}{c}\text { Wind Farm } \\
\text { Output (\% ) }\end{array}$ & Eigenvalue & $\begin{array}{c}\text { Frequency of oscilla- } \\
\text { tion ( Hz ) }\end{array}$ & $\begin{array}{c}\text { Damping } \\
\text { Ratio (\% ) }\end{array}$ \\
\hline 0 & $-0.667 \pm \mathrm{j} 11.159$ & 1.776 & 5.967 \\
10 & $-0.726 \pm \mathrm{j} 11.105$ & 1.767 & 6.524 \\
20 & $-0.795 \pm \mathrm{j} 11.045$ & 1.758 & 7.179 \\
30 & $-0.875 \pm \mathrm{j} 10.979$ & 1.747 & 7.945 \\
40 & $-0.965 \pm \mathrm{j} 10.908$ & 1.736 & 8.812 \\
50 & $-1.064 \pm \mathrm{j} 10.835$ & 1.724 & 9.773 \\
60 & $-1.168 \pm \mathrm{j} 10.764$ & 1.713 & 10.788 \\
70 & $-1.271 \pm \mathrm{j} 10.700$ & 1.703 & 11.796 \\
80 & $-1.364 \pm \mathrm{j} 10.647$ & 1.695 & 12.707 \\
90 & $-1.440 \pm \mathrm{j} 10.609$ & 1.688 & 13.450 \\
100 & $-1.528 \pm \mathrm{j} 10.565$ & 1.681 & 14.314 \\
\hline
\end{tabular}

Table 3. The eigenvalue, frequency and damping ratio of Mode II shifting with the output of wind farm varying.

\begin{tabular}{cccc}
\hline $\begin{array}{c}\text { Wind Farm } \\
\text { Output (\% ) }\end{array}$ & Eigenvalue & $\begin{array}{c}\text { Frequency of } \\
\text { oscillation ( Hz ) }\end{array}$ & $\begin{array}{c}\text { Damping } \\
\text { Ratio (\%) }\end{array}$ \\
\hline 0 & $-0.223 \pm \mathrm{j} 7.648$ & 1.217 & 2.915 \\
10 & $-0.226 \pm \mathrm{j} 7.643$ & 1.216 & 2.956 \\
20 & $-0.231 \pm \mathrm{j} 7.639$ & 1.216 & 3.023 \\
30 & $-0.238 \pm \mathrm{j} 7.635$ & 1.215 & 3.116 \\
40 & $-0.247 \pm \mathrm{j} 7.631$ & 1.215 & 3.235 \\
50 & $-0.257 \pm \mathrm{j} 7.629$ & 1.214 & 3.367 \\
60 & $-0.268 \pm \mathrm{j} 7.628$ & 1.214 & 3.511 \\
70 & $-0.279 \pm \mathrm{j} 7.629$ & 1.214 & 3.655 \\
80 & $-0.288 \pm \mathrm{j} 7.632$ & 1.215 & 3.771 \\
90 & $-0.296 \pm \mathrm{j} 7.636$ & 1.215 & 3.873 \\
100 & $-0.306 \pm \mathrm{j} 7.640$ & 1.216 & 4.002 \\
\hline
\end{tabular}

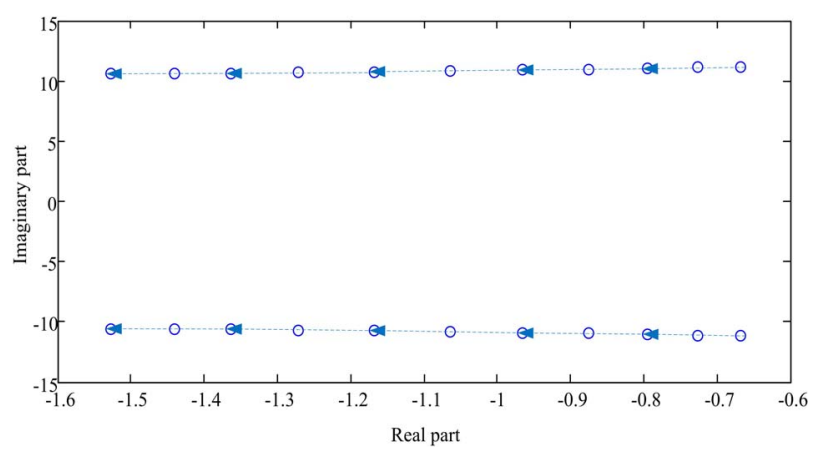

Figure 3. The eigenvalue of mode I shifting with the output of wind farm increasing.

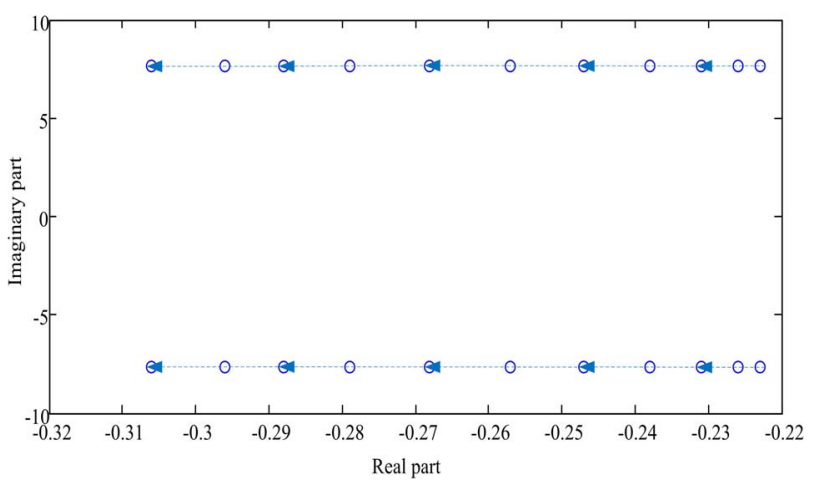

Figure 4. The eigenvalue of mode II shifting with the output of wind Farm varying.

At last, we study the relationship between the output of wind farm and the small-signal stability of power system, and get some preliminary conclusions. Since the 3-generator 9-bus WECC test system is just a small system, further research should be done in some larger systems.

\section{Acknowledgements}

The authors would like to thank the National High-tech Research and Development Program of China. (Grant No. 2012AA050208) for financial support.

\section{REFERENCES}

[1] China Wind Energy Association, "Statistics reports on China wind power construction achievements in 2011,”.

[2] H. Wang, Y. Zhang and Q. Zhou, "Wind Farm Model with DFIG for Small Signal Stability Study," Electric Utility Deregulation and Restructuring and Power Technologies (DRPT), 2011 4th International Conference on, 6-9 July 2011, pp. 303-307.

[3] C. Wang, L. Shi, L. Yao, L Wang and Y. Ni, "Small Signal Stability Analysis of the Large-scale Wind Farm with DFIGs," Proceedings of the CSEE, Vol. 30, No. 4, 2010, pp. 63-70.

[4] J. G. Slootweg and W. L. Kling, "The Imapct of Large Scale Wind Power Generation on Power System Oscillations,” Electric Power System Research, Vol. 67, No. 1, 2003, pp. 9-20. doi:10.1016/S0378-7796(03)00089-0

[5] L. Erlich and F. Shewarega, "Introduction of Wind Power Generation into the First Course in Power Systems," IEEE Power Engineering Society General Meeting, June 2007, pp. 1-8

[6] J. G. Slootweg, "Wind Power Modelling and Impact on Power System Dynamics,” Ph,D. Thesis, Technische Universiteit Delft, Delft, 2003.

[7] L. Erlich, J. Kretschmann, J. Fortmann, S. Mueller-Engelhardt and H. Wrede, "Modeling of Wind Turbines Based on Doubly-fed Induction Generators for Power System Stability Studies," IEEE Transactions on Power Systems. Vol. 22, No. 3, 2007, pp. 909-919. doi:10.1109/TPWRS.2007.901607 
[8] S. K. Salman and A. L. J. Teo, "Windmill Modeling Consideration and Factors Infulencing the Stability of a Grid-connected Wind Power Based Embedded Generator," IEEE Transactions on Power Systems. Vol. 18, No. 2, 2003, pp. 793-802. doi:10.1109/TPWRS.2003.811180

[9] F. Mei and B. C. Pal, "Modal Analysis of Grid Connected Doubly Fed Induction Generator," IEEE Transactions on Energy Conversion. Vol. 22, No. 3, 2007, pp. 728-736. doi:10.1109/TEC.2006.881080

[10] F. Mei and B. C. Pal, "Modeling and Small Signal Analy- sis of a Grid Connected Doubly Fed Induction Generator,” IEEE Power Engineering Society General Meeting, San Francisco, 12-16 June 2005,pp. 2101-2108.

[11] F. Wu, X. Zhang, K. Godfrey and P. Ju, "Modeling and Control of Wind Turbine with Doubly Fed Induction Generator” 2006 IEEE PES Power System Conference and Exposition, 29 October-1 November 2006, pp. 1404-1409. doi:10.1109/PSCE.2006.296507

[12] P. Kundur, "Power System Stability and Control" McGraw-Hill, Inc., New York, 1994. 